\title{
PENANAMAN SIKAP CINTA TANAH AIR DALAM PRAMUKA DI DABIN 5 UPTD PENDIDIKAN WIROSARI BROBOGAN
}

\author{
Sunu Dwi Priyoutomo'), Abdul Ngalim ${ }^{2)}$ \\ 1)UPTD Pendidikan Wirosari Grobogan \\ ${ }^{2}$ Magister Administrasi Pendidikan Sekolah Pascasarjana UMS Surakarta \\ email :sunudpu63@gmail.com
}

\begin{abstract}
The purpose of this study was to describe the attitude of patriotism planting in extracurricular activities scouts on the General Terms and Conditions Skills Special Skills in Dabin 5 UPTD Wirosari Subdistrict Grobogan. Type used is ethnographic qualitative research design. The research subjects were principals, teachers, and students. Data collection techniques used interviews, observation, and documentation. Data analysis techniques used the analysis of the flow of the process of data collection, data reduction, display, and verification, conclusion. The validity of the data sources and data used triangulation. The research result is habituation attitude of patriotism at the General Proficiency Requirements can memorize at least three daily prayers, prayers can carry, can maintain the cleanliness of the room school or place of worship, are able to help someone in the vicinity, follow the flag ceremony with wisdom. Exemplary attitude of patriotism at the General Proficiency Requirements can use Indonesian well and correctly, not littering, can show true deference to the Red and White Flag, can be memorized to sing the national anthem Indonesia Raya. SKK is used to apply the attitude of patriotism is SKK singer, conductor SKK, SKK P3K, SKK Explorer / Searching for Traces, SKK Camping, SKK Greening.
\end{abstract}

Keywords: patriotism, extracurricular, planting, scout

Abstrak: Tujuan Penelitian ini adalah untuk mendeskripsikan penanaman sikap cinta tanah air dalam kegiatan ekstrakurikuler pramuka pada Syarat Kecakapan Umum (SKU) dan Syarat Kecakapan Khusus ( SKK ) di Dabin 5 UPTD Pendidikan Kecamatan Wirosari Kabupaten Grobogan. Jenis Penelitian kualitatif desain etnografi. Subyek penelitian kepala sekolah, guru dan siswa. Teknik pengumpulan data dengan wawancara, observasi, dan dokumentasi. Teknik analisis data dengan analisis alur dengan proses pengumpulan data, reduksi data, display, dan verifikasi, simpulan. Keabsahan data triangulasi data dan sumber. Hasil penelitian adalah pembiasaan sikap cinta tanah air pada Syarat Kecakapan Umum (SKU) dapat menghafal sedikitnya 3 doa harian, dapat melaksanakan shalat berjamaah, dapat memelihara kebersihan ruangan sekolah atau tempat ibadah, dapat menolong seseorang di sekitarnya, mengikuti upacara bendera dengan hikmat. Keteladanan sikap cinta tanah air pada Syarat Kecakapan Umum (SKU) dapat menggunakan Bahasa Indonesia dengan baik dan benar, tidak membuang sampah sembarangan, dapat menunjukan sikap hormat yang benar kepada Bendera Merah Putih, dapat dengan hafal menyanyikan Lagu Kebangsaan Indonesia Raya. SKK yang digunakan untuk menanamkan sikap cinta tanah air adalah SKK Penyanyi, SKK Dirigen, SKK P3K, SKK Penjelajah/Mencari Jejak, SKK Berkemah, SKK Penghijauan.

Kata kunci: cinta tanah air,ekstrakurikuler,penanaman,pramuka 


\section{Pendahuluan}

Setiap warga negara Indonesia diharapkan memiliki nasionalisme yang tinggi karena dengan nasionalisme yang tinggi dapat menunjukan eksistensi bangsa dan negara di mata dunia internasional. Nasionalisme tidak tumbuh dengan sendirinya, akan tetapi harus ada upaya dari warga negara untuk berusaha memiliki sikap rasa bangga dan cinta terhadap negara Indonesia.

Dunia pendidikan dewasa ini menghadapi berbagai masalah yang kompleks, yang perlu mendapat perhatian. Salah satu masalah tersebut adalah menurunnya rasa kebangsaan. Hal ini terjadi karena faktor-faktor yang mempengaruhinya. Salah satunya karena adanya globalisasi. Globalisasi adalah suatu proses tatanan masyarakat yang mendunia dan tidak mengenal batas wilayah.

Masyarakat Indonesia, khususnya anak muda, banyak yang lupa akan identitas diri sebagai bangsa Indonesia, karena gaya hidupnya cenderung meniru budaya barat yang oleh masyarakat dunia dianggap sebagai kiblat. Salah satu realitanya adalah anak muda lebih tertarik terhadap produk-produk luar negeri. Pengaruh gaya hidup barat tersebut secara perlahan akan mengikis rasa nasionalisme generasi muda. Westernisasi secara nyata terus menggerus nasionalisme generasi muda Indonesia. Kondisi seperti ini tentu sangat mengkhawatirkan. Ilahi (2012: 10), mengungkapkan bahwa:

"Di era globalisasi sekarang kobaran semangat nasionalisme generasi muda mulai luntur. Lunturnya semangat nasionalisme generasi muda bisa saja menjadi ancaman (treatment) terhadap terkikisnya nilai-nilai patriotism yang menjadi landasan kecintaan kita terhadap bumi pertiwi tercinta."

Menurut Takahiro Kondo and Xiaoyan $\mathrm{Wu}$, (2011:23) patriotism afanatical belief in and love of the current state as supreme. Menurut Boonghee Yoo, (2005:14) Patriotism refers to love for and a sense of pride in one's own country, a sacrificial devotion to it, respect and loyalty to its people, and protection of it against out-groups.

Arti dari cinta tanah air adalah cinta kepada Negara tempat kita dilahirkan, dibesarkan dan memperoleh kehidupan di dalamnya. Karena dari Negara tersebut semua yang kita butuhkan akan kita dapatkan. Cinta tanah air adalah sama saja rela berkorban demi kepentingan Negara.

Rasa cinta tanah air adalah rasa kebanggaan, rasa memiliki, rasa menghargai, rasa menghormati dan loyalitas yang dimiliki oleh setiap individu pada negara tempat dimana ia tinggal. Yang tercermin dari perilaku membela tanah airnya, menjaga dan melindungi tanah airnya, rela berkorban demi kepentingan bangsa dan negaranya, mencintai adat atau budaya yang ada di negaranya dengan melestarikan alam dan lingkungan. Cinta Tanah Air merupakan pengamalan dan wujud dari sila Persatuan Indonesia yang dapat diwujudkan dalam kehidupan seharihari di keluarga, sekolah dan masyarakat. Tiap-tiap warga negara berhak dan wajib ikut serta dalam usaha pembelaan negara, syarat-syarat pembelaan negara diatur dalam Undang - Undang. Kesadaran cinta tanah air itu pada hakikatnya berbakti kepada negara dan kesediaan berkorban membela negara.

Cintatanahairdanbangsapadahakekatnya adalah berbuat sesuatu yang mengharumkan nama tanah air dan bangsa. Pada keadaan saat ini apa yang bisa dibanggakan dari negara dan bangsa Indonesia? Kalau saja rasa cinta tanah air dan bangsa sekali lagi bisa menjadi faktor yang memotivasi bangsa Indonesia, ada kemungkinan bangsa Indonesia akan bisa bangkit kembali dengan masyarakatnya bisa menghasilkan karya-karya yang membanggakan kita sebagai bangsa.

Penelitian ini memiliki dua tujuan (1) Untuk mendeskripsikan penanaman sikap cinta tanah air dalam kegiatan ekstrakulikuler pramuka pada Syarat Kecakapan Umum ( SKU ) di Dabin 5 UPTD Pendidikan Kecamatan Wirosari Kabupaten Grobogan. (2) Untuk mendeskripsikan penanaman sikap 
cinta tanah air dalam kegiatan ekstrakulikuler pramuka pada Syarat Kecakapan Khusus ( SKK ) di Dabin 5 UPTD Pendidikan Kecamatan Wirosari Kabupaten Grobogan.

\section{Metode}

Jenis penelitian yang digunakan dalam penelitian ini adalah penelitian kualitatif, yaitu rangkaian kegiatan atau proses menjaring informasi dari kondisi sewajarnya dalam kehidupan suatu obyek, dihubungkan dengan suatu masalah, baik dari sudut pandang teoritis maupun praktis.Menurut Sugiyono (2008: 9), metode penelitian kualitatif sering disebut metode penelitian naturalistik karena penelitiannya dilakukan pada kondisi yang alamiah.Penelitian ini berlokasi di UPTD Pendidikan Kecamatan Wirosari Kabupaten Grobogan.Waktunya dari bulan Juli 2015 s/d Januari 2016.

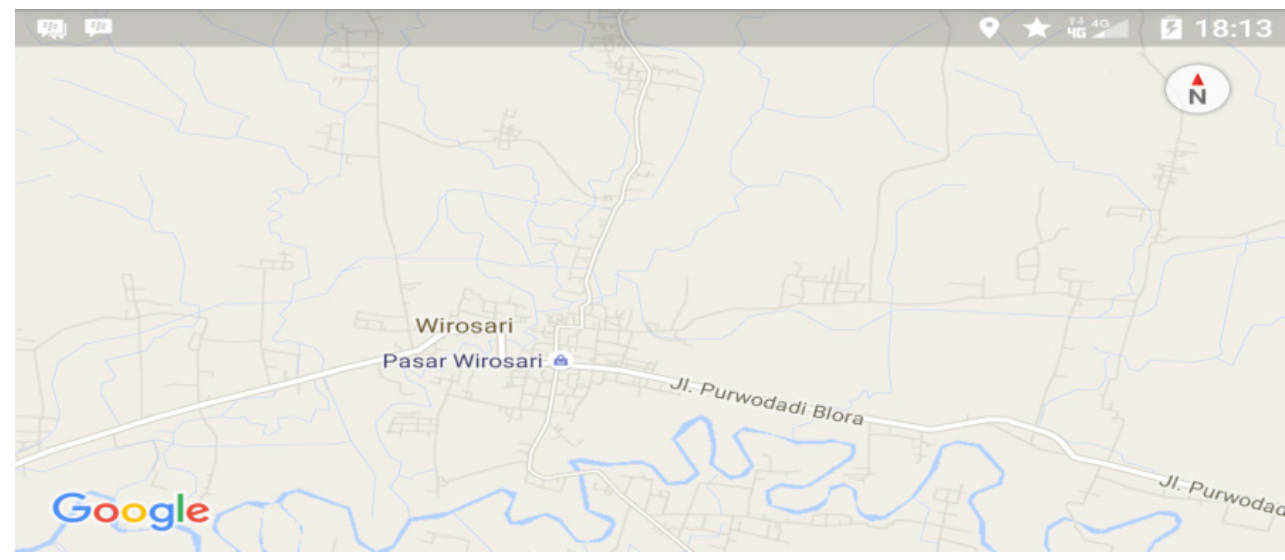

Subyek penelitiannya adalah kepala sekolah, guru, dan siswa SD di Dabin 5 UPTD Pendidikan Kec.Wirosari Grobogan. Penelitian ini menggunakan pendekatan etnografi. Teknik pengumpulan data yang digunakan dalam penelitian ini adalah dengan analisis wawancara,observasi dan dokumentasi. Keabsahan data dilakukan dengan triangulasi metode dan sumber. Menurut Moleong (2007:330). "Peneliti menggunakan triangulasi sebagai teknik untuk mengecek keabsahan data. Di mana dalam pengertiannya triangulasi adalah teknik pemeriksaan keabsahan data yang memanfaatkan sesuatu yang lain dalam membandingkan hasil wawancara terhadap objek penelitian”. Teknik analisa data yang digunakan dalam penelitian ini adalah analisis model interaktif (Interactive Model of Analysis). Menurut Miles dan Huberman (2007:16) dalam model ini ada tiga komponen analisis. (1)Reduksi data (data reduction) (2) Penyajian data (data display) (3)Penarikan kesimpulan (conclusion drawing)

\section{Hasil dan Pembahasan}

1. Penanaman sikap cinta tanah air dalam kegiatan ekstrakulikuler pramuka pada Syarat Kecakapan Umum ( SKU ) di Dabin 5 UPTD Pendidikan Kecamatan Wirosari Kabupaten Grobogan

Pendidikan Kepramukaan sebagai kegiatan ekstrakurikuler di Dabin 5 UPTD Pendidikan Kecamatan Wirosari Grobogan merupakan tanggung jawab kepala sekolah dengan pelaksana pembina pramuka. Pembina pramuka adalah guru kelas/guru mata pelajaran yang telah memperoleh sertifikat paling rendah Kursus Mahir Dasar ( KMD ) atau Pembina Pramuka yang bukan guru kelas/guru mata pelajaran. Menurut Sopiatin (2010: 99) ekstrakurikuler adalah kegiatan wahana pengembangan pribadi peserta didik melalui berbagai aktivitas, baik yang terkait langsung maupun tidak terkait langsung dengan kurikulum, sebagai bagian tidak terpisahkan dari tujuan kelembagaan.

Kegiatan eksrakurikuler pramuka di di Dabin 5 UPTD Pendidikan Kecamatan 
Wirosari Grobogan harus dapat dilaksanakan dengan efektif. Oleh karena itu penanaman sikap cinta tanah air pada kegiatan ekstrakurikuler pramuka berpedoman pada Syarat Kecakapan Umum (SKU) dan Syarat Kecakapan Khusus (SKK). Pelaksanaan ekstrakurikuler pramuka di Dabin 5 UPTD Pendidikan Kecamatan Wirosari Grobogan dilaksanakan pada hari Jumat sore. Syarat Kecakapan Umum (disingkat SKU) adalah syarat kecakapan yang wajib dimiliki oleh setiap anggota pramuka sebagai prasyarat untuk mendapatkan Tanda Kecakapan Umum. SKU disusun menurut pembagian golongan usia Pramuka yaitu golongan Siaga, golongan Penggalang, golongan Penegak dan golongan Pandega. SKU sebagai alat pendidikan, merupakan rangsangan dan dorongan bagi para Pramuka untuk memperoleh kecakapan-kecakapan yang berguna baginya, untuk berusaha mencapai kemajuan, dan untuk memenuhi persyaratan sebagai anggota Gerakan Pramuka.

Pembiasaan sikap cinta tanah air berdasarkan Syarat Kecakapan Umum (SKU) yang diajarkan dalam kegiatan ekstrakulikuler pramuka di Dabin 5 UPTD Pendidikan Kecamatan Wirosari Grobogan diantaranya adalah dapat menghafal sedikitnya 3 doa harian, dapat melaksanakan shalat berjamaah, dapat memelihara kebersihan ruangan sekolah atau tempat ibadah, dapat menolong seseorang di sekitarnya, mengikuti upacara bendera dengan hikmat. Keteladanan sikap cinta tanah air pada Syarat Kecakapan Umum (SKU) yang dipraktikkan dalam kegiatan ekstrakulikuler pramuka di Dabin 5 UPTD Pendidikan Kecamatan Wirosari Grobogan diantaranya adalah dapat menggunakan Bahasa Indonesia dengan baik dan benar, tidak membuang sampah sembarangan, dapat menunjukan sikap hormat yang benar kepada Bendera Merah Putih, dapat dengan hafal menyanyikan Lagu Kebangsaan Indonesia Raya. Menurut Aqib \& Sujak (2011: 81), Gerakan pramuka adalah gerakan pendidikan kaum muda yang menyelenggarakan kepramukaan dengan dukungan dan bimbingan anggota dewasa. Sebagai gerakan pendidikan, usaha gerakan pramuka tidak lepas dari pola dasar pendidikan nasional dan merupakan salah satu sarana pendidikan, disamping sarana pendidikan yang lain (keluarga, sekolah, kelompok sebaya, lingkungan kerja dan masyarakat).

Dalam menanamkan rasa cinta tanah air aktivitas siswa dalam kegiatan ekstrakurikuler pramuka yaitu dengan mengikuti upacara pembukaan, absensi kehadiran siswa, mendengarkan dan mencatat pemberian materi yang berhubungan dengan penanaman rasa cinta tanah air, yang dilakukan Pembina pramuka, mempraktikkan materi yang dijelaskan oleh Pembina dan mengadakan permainan-permainan, dan ditutup dengan upacara penutupan. Penelitian ini didukung dengan penelitian yang dilakukan oleh Lewis (2004) dalam penelitiannya yang berjudul The Relation Between Extracurricular Activities With Academic And Social Competencies In School Age Children: A Meta-Analysis. Tujuan penelitian ini adalah untuk mengintegrasikan studi partisipasi dari tahun 1990-an dan memberikan informasi kepada anak sebagai dampak partisipasi kegiatan ekstrakurikuler pada karakteristik pendidikan dan psikososial. Sebagai kesimpulan, hasil terbaik bagi anak-anak dan remaja yang membawa ke perkembangan yang baik adalah kegiatan terstruktur sesuai dengan tahapan perkembangan. Selain itu, keuntungan akademik dan sosial dari kegiatan ekstrakurikuler yang telah diteliti dalam penelitian ini dapat digunakan untuk menginformasikan perencanaan dan pelaksanaan program bagi kegiatan belajar siswa.

2. Penanaman sikap cinta tanah air dalam kegiatan ekstrakulikuler pramuka pada Syarat Kecakapan Khusus ( SKK ) di Dabin 5 UPTD Pendidikan Kecamatan Wirosari Kabupaten Grobogan.

Penerapan sikap cinta tanah air dalam Kegiatan Ekstrakurikuler Pramuka di Dabin 5 UPTD Pendidikan Kecamatan Wirosari 
Grobogan berpedoman pada prinsip Dasar Kepramukaan yang sasaran akhirnya pembentukan watak, akhlak dan budi pekerti luhur, yang disesuaikan dengan keadaan, kepentingan dan perkembangan masyarakat dan bangsa Indonesia. Semua hasil yang diperoleh siswa tersebut nantinya dapat digunakan siswa sebagai bekal menghadapi masa depan. MenurutElly Sri Melinda (2013: 2) mengemukakan bahwa dalam kegiatan kepramukaan siswa selalu diarahkan untuk mengikuti berbagai kegiatan yang menarik, menantang, kreatif, dan menyenangkan sehingga para peserta didik dapat memiliki sikap disiplin, berani, menghargai orang lain, peduli lingkungan, cinta alam dan memiliki kemandirian. Pendekatan dalam kegiatan kepramukaan adalah pendekatan edukatif yaitu menyajikan kegiatan kepramukaan yang mengandung nilai-nilai pendidikan dengan sistem beregu sehingga dapat mengembangkan sikap bekerjasama, bersikap menjadi anggota kelompok yang baik, menjadi pemimpin, dipimpin dan mempimpin, saling menghargai dan saling mendukung.

Penerapan sikap cinta tanah air dalam Kegiatan Ekstrakurikuler Pramuka di Dabin 5 UPTD Pendidikan Kecamatan Wirosari Grobogan juga mengacu pada Syarat Kecakapan Khusu (SKK). Syarat Kecakapan Khusus (SKK) adalah syarat kecakapan pada bidang tertentu berdasarkan pilihan pribadi dalam pengembangan minat dan bakat peserta didik.Sehingga mendapatkan Tanda Kecakapan Khusus (TKK) . Tanda Kecakapan Khusus (TKK) diperoleh setelah melalui ujian-ujian. SKK yang digunakan untuk menerapkan sikap tanah air diantaranya adalah SKK Penyanyi, SKK Dirigen, SKK P3K, SKK Penjelajah/Mencari Jejak, SKK Berkemah, SKK Penghijauan. Peneliti melihat ketika upacara bendera hari Senin belangsung pada saat menyanyikan lagu Indonesia Raya yang menjadi dirigen ternyata bukan gurunya melainkan siswa yang ternyata telah lulus ujian di kepramukaan dan mendapatkan TKK Dirigen. Kemudian di kelompok barisan tersendiri ada sekelompok anak yang berseragam "dokter kecil”, ternyata adalah regu PPPK.Mereka bertugas sebagai regu penolong bila ada anak yang mengalami pingsan.Ternyata mereka juga telah lulus ujian SKK PPPK di kepramukaan.

Tujuan SKK adalah untuk mendorong dan merangsang siswa agar berusaha memperoleh sejumlah kecakapan sehingga diharapkan dapat mengatasi kesulitan dan mampu untuk membaktikan dirinya kepada masyarakat. Para siswa yang mengikuti ekstrakulikuler pramuka mempunyai pengetahuan, kecakapan dan kemampuan sehingga dapat menimbulkan rasa bangga memiliki tanda kecakapan serta akan lebih mencintai tanah airnya. Fungsi kepramukaan menurut Kwarnas (2011: 21) adalah kegiatan menarik bagi siswa atau pemuda, pengabdian bagi orang dewasa dan alat bagi masyarakat dan organisasi. Bagi siswa SD kegiatan pramuka merupakan kegiatan yang menyenangkan dan mengandung pendidikan. Mengandung pendidikan di sini diartikan sebagai kegiatan yang dapat menyiapkan siswa menjadi pribadi yang bertanggung jawab, disipilin, peduli, menemukan dan mengembangkan minat dan bakat pribadinya. Karena itu kegiatan harus mempunyai tujuan dan aturan, jadi bukan kegiatan yang hanya bersifat hiburan saja.

Dalam kegiatan kepramukaan Dabin 5 UPTD Pendidikan Kecamatan Wirosari Grobogan disajikan berbagai kegiatan yang mengandung nilai-nilai pendidikan yang dapat mengembangkan sikap, nilai serta keterampilan melalui berbagai kegiatan yang rekreatif, edukatif, di alam terbuka. Melalui berbagai kegiatan peserta didik memperoleh pengalaman, keterampilan dan pengetahuan. Kegiatan dikemas bernuansa perjuangan, budaya yang dapat memberikan kesan moral sehingga menggerakkan jiwa dan membentuk watak serta menumbuhkan sikap cinta tanah air. Pembinaan watak, kepribadian, dan akhlak mulia dilakukan melalui kegiatan keimanan dan ketakwaan kepada Tuhan 
Yang Maha Esa, Kesadaran berbangsa dan bernegara, pengamalan moral pancasila, pemahaman sejarah perjuangan bangsa, rasa percaya diri, kepedulian dan tanggung jawab serta disiplin (Azrul Azwar, 2010: 30).

Tujuan dari Gerakan Pramuka adalah membentuk setiap angggota pramuka agar memiliki kepribadian yang beriman, bertakwa, berakhlak mulia, berjiwa patriotik, taat hukum, disiplin, menjunjung tinggi nilainilai luhur bangsa, dan memiliki kecakapan hidup sebagai kader bangsa dalam menjaga dan membangun Negara Kesatuan Republik Indonesia, mengamalkan Pancasila, serta melestarikan lingkungan hidup.

Program-program untuk mendukung menumbuhkan sikap rasa cinta tanah air dalam kegiatan pramuka di Dabin 5 UPTD Pendidikan Kecamatan Wirosari Grobogan diantaranya adalah dengan melakukan kegiatan perkemahan yang di dalamnya terdapat kegiatan seperti kegiatan kebersihan / bakti masyarakat. Mengadakan kegiatan upacara pembukaan dan penutupan pada setiap kegiatan pramuka. Dalam pelaksnaan kegiatan kepramukaan percakapan menggunakan Bahasa Indonesia yang baik dan benar.

Tujuan yang ingin dicapai dalam kegiatan berkemah sehubungan dengan perwujudan sikap cinta tanah air, selain hidup mandiri, agar anak mencintai lingkungannya, mencintai teman -temannya, menghomati guru / pembina, bapak ibunya dan mau hidup gotong royong. Kegiatan perkemahan pramuka merupakan salah satu solusi yang efektif dalam rangka meningkatkan dan membangun rasa kebangsaan yang tinggi, kecintaan terhadap tanah air dan semangat gotong royong yang kuat, melatih disiplin, mandiri dan terampil. Penelitian ini sejalan dengan penelitian yang dilakukan oleh Nierman (2010) dengan judul penelitian Skill-based Scouting of Open Management Content membahas mengenai pengelolaan keterampilan dalam kegiatan pramuka. Disebutkan bahwa untuk mendapatkan SDM yang bagus perlu pencarian atau pemberian keterampilan. Hasil penelitian ini menunjukkan bahwa peningkatan SDM dalam kegiatan pramuka digunakan metode keterampilan berbasis content yang memberikan materi-materi khusus untuk skill ( keterampilan )

Peran dari pembina dalam penanaman nilai cinta tanah air sangat penting, karena pembina merupakan contoh teladan bagi anak-anak dengan harapkan pembina pramuka memiliki rasa cinta tanah air yang tinggi, sehingga anak-anak akan meneladani, mencontoh apa yang dilakukan oleh pembina pramuka. Selain itu pembina juga harus mampu memberikan kegiatan yang bermanfaat dan mendidik.

\section{Simpulan}

Penanaman sikap cinta tanah air dalam Kepramukaan sebagai kegiatan ekstrakurikuler merupakan tanggung jawab kepala sekolah dengan pelaksana pembina pramuka yang telah memperoleh sertifikat paling rendah Kursus Mahir Dasar (KMD). Pelaksanaan eksrakurikuler pramuka berpedoman pada Syarat Kecakapan Umum (SKU) dan Syarat Kecakapan Khusus (SKK). SKU adalah syarat kecakapan yang wajib dipenuhiolehpesertadidiksebagaisyaratuntuk mendapatkan tanda kecakapan. Pembiasaan sikap cinta tanah air pada Syarat Kecakapan Umum (SKU) yang diajarkan dalam kegiatan ekstrakulikuler pramuka diantaranya adalah dapat menghafal sedikitnya 3 doa harian, dapat melaksanakan shalat berjamaah, dapat memelihara kebersihan ruangan sekolah, atau tempat ibadah, dapat menolong seseorang di sekitarnya, mengikuti upacara bendera dengan hikmat. Keteladanan sikap cinta tanah air pada Syarat Kecakapan Umum (SKU) yang dipraktikkan dalam kegiatan ekstrakulikuler pramuka diantaranya adalah dapat menggunakan Bahasa Indonesia dengan baik dan benar, tidak membuang sampah sembarangan, dapat menunjukan sikap hormat yang benar kepada bendera merah putih, dapat dengan hafal menyanyikan Lagu Kebangsaan Indonesia Raya. Selain pembiasaan dan 
keteladanan dalam menanamkan sikap cinta tanah air juga diberikan materi yang lain yaitu mau mengikuti upacara di sekolah maupun upacara kepramukaan,dapat menyebutkan sila-sila Pancasila,dapat menarikan salah satu tari tradisional atau kreasi baru, dapat mengetahui dan memilah sampah organik dan anorganik dan mau mengikuti karnaval di sekolah atau di masyarakat.Pelaksanaan kegiatan dikelompok menjadi regu-regu yang dipimpin oleh pimpinan regu.

Penerapan sikap cinta tanah air dalam Kegiatan Ekstrakurikuler Pramuka di Dabin 5 UPTD Pendidikan Kecamatan Wirosari Grobogan berpedoman juga pada Syarat Kecakapan Khusu (SKK). SKK adalah syarat kecakapan pada bidang tertentu berdasar pilihan pribadi dalam bakat dan minat peserta didik.SKK yang digunakan untuk menerapkan sikap tanah air diantaranya adalah SKK Penyanyi, SKK Dirigen, SKK P3K, SKK Penjelajah atau Mencari Jejak,
SKK Berkemah, dan SKK Penghijauan. Tujuan SKK adalah untuk mendorong dan merangsang siswa agar berusaha memperoleh sejumlah kecakapan sehingga diharapkan dapat mengatasi kesulitan dan mampu untuk membaktikan dirinya kepada masyarakat. Para siswa yang mengikuti ekstrakulikuler pramuka mempunyai pengetahuan, kecakapan dan kemampuan sehingga dapat menimbulkan rasa bangga memiliki tanda kecakapan serta akan lebih mencintai tanah airnya. Tujuan dari gerakan pramuka adalah membentuk kepribadian yang beriman, bertakwa, berakhlak mulia, berjiwa patriotik, taat hukum, disiplin, menjujung nilai-nilai luhur bangsa, mengamalkan Pancasila dan melesterikan lingkungan.Sekolah di Dabin 5 UPTD Pendidikan Kecamatan Wirosari menyiapkan rencana kegiatan pramuka sesuai buku panduan kegiatan pramuka, buku SKU dan SKK .

\section{Daftar Pustaka}

Asep Herry Hernawan,dkk. 2011. Pengembangan Kurikulum dan Pembelajaran. Jakarta,Penerbit UT, Cet 15

Azrul Azwar. 2010. Gerakan Pramuka: Anggaran Dasar dan Anggaran RumahTangga. Jakarta: Tunas Media.

Bachsan. 2010. Pramuka. http://man1samarinda.sch.id/index.php/ekskul/36-ekstrakul/81pramuka. Diakses pada tanggal 18 April 2011.

Choudhur. 2003. "Promoting Value Education through Children's Literature". Journal Of Value Education. Vol 1 No 3 . Pg: 29-36

Cousse. 2009. "Youth work and its forgotten history. A view from Flanders". Journal Of Academic Research. Vol 1 No 1. Pg: 1-16

Emzir. 2007. Metode Penelitian Pendidikan Kualitatif \& Kuantitatif. Jakarta: Rajawali Pers.

Kwarnas. 2010. Kursus Pembina Pramuka Mahir Tingkat Dasar. Jakarta: Kwartir Nasional Gerakan Pramuka.

Kwarnas. 2011. Syarat-Syarat Kecakapan Umum (SKU) Golongan Penegak dan Pandega. Jakarta: Kedai Kwartir Naional Pramuka.

Lord Baden .2010. Scouting For Boys. A Handbookfor Instruction in Good Citizenship Through Woodcraft By Lord Baden-Powell Of Gilwell. Founder of the Boy Scout Movement.

Moleong, Lexy. 2012. Metodologi Penelitian Kualitatif, cet. 13. Bandung: PT. Remaja Rosdakarya.

Nierman. 2010. "Skill-based Scouting of Open Management Content". Journal of Scout. Vol 
1 No 1. Pg: 1-6.

Nikki Wilson.2009. Impact of Extracurricular Activities on Students. The Graduate School University of Wisconsin-Stout May, 2009

Oliver. 2010. What Makes a Leader? Mapping Leadership in our Region. Research Fellow.

Pusdiklatda DIY Wirajaya. (2012). Buku Panduan Kursus Pembina Pramuka Mahir Tingkat Dasar. Yogyakarta: PGSD FIP UNY.

Rosemary O. Ekechukwu. 2014. Leadership Education through Extracurricular Activities in Tertiary Institutions in Nigeria. Academic Research International Vol. 5(3) May 2014

Sugiyono, 2012. Metode Penelitian Pendidikan Pendekatan Kuantitatif, Kualitatif, dan R\&D. Bandung: Alfabeta

Suprapto, dkk. 2010.Pendidikan Kewarganegaraan Kelas X SMA/MA 1. Jakarta:PT Bumi Aksara.

Undang-Undang Republik Indonesia No 12 Tahun 2010 tetang Gerakan Pramuka. Jakarta: Kedai Kwartir Nasional Gerakan Pramuka.

Zainal Aqib \& Sujak. 2011. Panduan dan Aplikasi Pendidikan Karakter.Bandung: Yrama Widya. 